\title{
Analysis of Wind Power Grid Connection Based on MATLAB
}

\author{
Yuyang Mao ${ }^{1, \mathrm{a}}$, Xiaolong $\mathrm{Wang}^{1}$ and Zhiqiang Wang ${ }^{1}$ \\ ${ }^{1}$ North China Electric Power University, Beijing 102206, China
}

\begin{abstract}
As the proportion of new energy sources such as wind power and photovoltaics in the power system continues to increase, their volatility and intermittentness have also brought new challenges to the stable operation of the power grid. The impact of the decline in power quality caused by a large number of wind power grids has become increasingly significant. This article analyzes and summarizes the development, status quo of wind power and the current problems of a large number of wind power grid connections. First, it briefly describes the history of wind power and the current development of wind power, and uses MATLAB to establish models of variable speed wind turbines connected to the grid. The models are used to analyze the output characteristics of wind turbines under normal operating conditions and faulty operating conditions. Finally, the impact of a large number of wind power grids on the power system is studied.
\end{abstract}

\section{Introduction}

With the continuous development of the industrialization of world, the energy of world demand is increasing year by year, but the reserves of fossil energy are limited. The shadow of the energy crisis looms over the production and life of mankind. The governments of various countries have begun to realize that we cannot just take care of the needs of the present generation and fish for nothing, while ignoring the future and destiny of future generations.

As the proportion of clean energy in the power grid is increasing year by year, the world's dependence on fossil energy is decreasing year by year [2]. Clean energy power generation technology is not only a hot spot that the international community pays attention to, but also the key to the transformation of the power industry[3]

In the international research and development of renewable energy, wind power technology is currently the most mature renewable energy technology besides hydropower, with the characteristics of safety, greenness, and abundant reserves. The total available wind energy in the world is 53000TW'h/year [4]. Compared with traditional fossil energy, wind energy is a permanent and massively stored local resource, which is inexhaustible and inexhaustible. It does not have the fuel requirement of thermal power. After a wind farm is established in a suitable location, it only needs to monitor and maintain the operation of the wind turbine to obtain a steady stream of electrical energy. Especially at the time when traditional energy sources are gradually depleted and the earth's pollution is gradually increasing, wind power technology with large-scale development potential and development value has received increasing attention and attention from various countries [5]. However, due to the various characteristics of wind energy, there are big problems in the application of wind energy:

(1) Lack of stability. Wind power is obviously unpredictable. It is difficult to predict the magnitude and direction of the wind, and whether it will start or not. As a result, wind power generation cannot be effectively controlled like thermal power and other traditional power generation methods. Therefore, wind power generation All have the characteristics of randomness and intermittentness. This leads to poor quality of wind power, regardless of frequency and voltage, it is difficult to maintain a stable state.

(2) Wind energy cannot be stored. Wind energy cannot be stored like other forms of power generation, because wind energy can only be generated in windy weather, and cannot be stored like hydropower and thermal power. In order to avoid the impact on the grid due to the intermittency of wind power generation, energy storage equipment is generally installed on the generator set, thus increasing the cost of wind power generation.

(3) The location of the power plant is relatively remote. Most of my country's wind farms are located in the Northwest, North China and Northeast regions. These regions have very rich wind energy resources and have good prospects for wind power generation. However, the geographical location of wind power generation sites is relatively remote from other power plants. Therefore, when wind energy is connected to the grid, a larger investment is required.

The integration of a large number of wind power to the grid brings more than just positive factors. If the grid's capacity to absorb wind power is not enough, it will often lead to a large amount of wind curtailment.

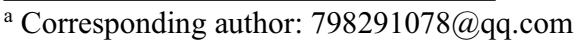




\section{Sructure and control of power generation system}

\subsection{Overview}

The rotation of the earth and the temperature difference make the air flow, and the kinetic energy of the flowing air is called wind energy. The equipment that converts wind energy into electrical energy is a wind turbine. In the history of wind power development, humans have designed a variety of models, from the earliest fixedspeed wind motors to the later variable-speed wind motors, and even so far, there are still new models under development. As of the early 1990s, Danish wind motors (fixed-speed wind motors) were dominant because, compared with variable-speed wind motors, fixed-speed wind motors had the characteristics of simple structure, low price, and good economy[5]. The working principle of the fixed-speed wind turbine is to use the wind wheel to convert the kinetic energy of the wind into mechanical energy, and then transmit it to the rotor through the gear shaft system. The rotor rotates and cuts the magnetic field to convert the mechanical energy into electrical energy, and finally transmits it to the power system. In the mid-1990s, in the field of megawatt wind turbines, variable-speed and variable-pitch wind turbines with wind speed feedback were soon introduced. Variablespeed wind turbines can more easily adapt to wind conditions in different regions and at different times, so wind turbines above $2 \mathrm{MW}$ adopt this scheme [6].

\subsection{Principle and modeling of doubly-fed variable speed wind turbine}

\subsubsection{Structure of doubly-fed variable speed wind turbine}

The wind blows the wind wheel to rotate, and then transmits it to the wound asynchronous generator through the shaft system. The stator winding of the generator is directly connected to the power system, and the rotor It is connected to the power system through two PWM converters. The reason DFIG is called a doublyfed motor is because the output power of the wind motor to the grid includes the output power on the stator side and the slip power on the rotor side via the PWM converter. In the dual PWM converter, the three-phase connection to the rotor of the asynchronous induction generator is the Rotor Side Convert (RSC), and the one directly connected to the grid is called grid-side converter. The main functions of the rotor-side converter are: 1. It can realize the $\mathrm{AC}$ excitation of the generator rotor, and the output voltage of the wind turbine can be kept constant by changing the excitation current to avoid inrush current during grid connection; 2. The vector control can be used to achieve separation Control the active power and reactive power of DFIG independently, so that active and reactive power do not affect each other; 3. Maximize the utilization rate of wind energy and adjust the power factor at the same time. The main functions of the grid-side converter are: 1. Maintain a stable DC bus voltage and deliver slip power to the power system; 2. Control reactive power on the stator side.

\subsubsection{The working principle of double feedback induction variable speed wind motor}

DFIG can change the angle of attack of the airflow on the blades according to the wind speed through the pitch control system, so that the speed of the wind wheel is controlled within a certain range, so that the generator output power is kept within the rated range.

The doubly-fed induction variable speed wind turbine relies on the pitch control system as the outer ring of the entire power generation system, which is the core component of the wind turbine. Corresponding to different wind speeds, the pitch angle control system can control the blades to rotate to the programmed position. When the starting wind speed is low, the wind motor blades rotate to the corresponding angle, so that the wind motor can start quickly; when the wind speed is higher than the rated wind speed At this time, the pitch control system adjusts the pitch of the blades and changes the angle of attack of the airflow on the blades, thereby changing the power generation efficiency of the wind turbine, so that the output power of the wind turbine is within the rated range.

\section{Wind power grid-connected simulation}

In order to research the simulation of wind power grid connection, this paper uses MATLAB to establish a simulation system of infinite power constant speed wind turbines. The model is shown in Figure 1.

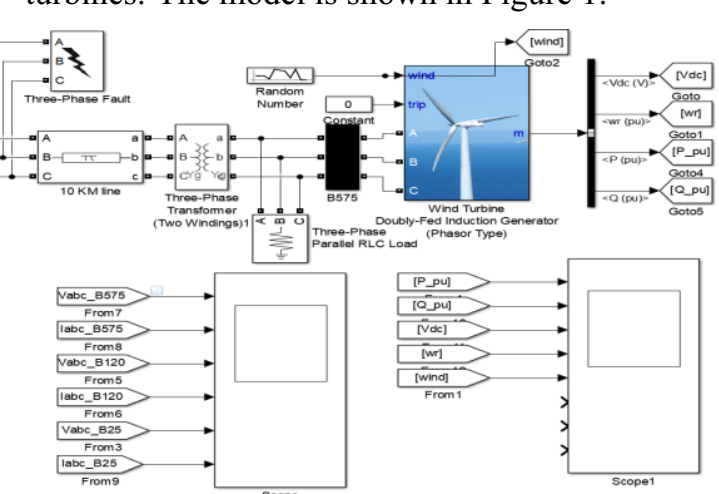

Figure 1. Simulation Model of Variable Speed Wind Turbine Based on Double Feedback Asynchronous Induction Generator 


\subsection{Output characteristics of dual-feedback asynchronous variable-speed wind turbine}

The variable-speed wind generator adopts a dualfeedback asynchronous induction wind generator. It including a PWM converter based on AC/DC/AC IGBT and a wound rotor induction generator. The stator side winding is directly connected to the $50 \mathrm{hz}$ power grid, and the rotor side is used for frequency conversion and speed regulation through AC/DCIAC frequency converters. DFIG technology extracts the maximum energy from the wind at low wind speeds by optimizing the turbine speed, while minimizing the mechanical stress of the turbine during gusts. In the designed simulation model, the wind speed is set to fluctuate at 14 $\mathrm{m} / \mathrm{s}$ with a random generator module. The output characteristics of the wind turbine are shown in Figure 2, and the voltage and current of each node are shown in Figure 3.

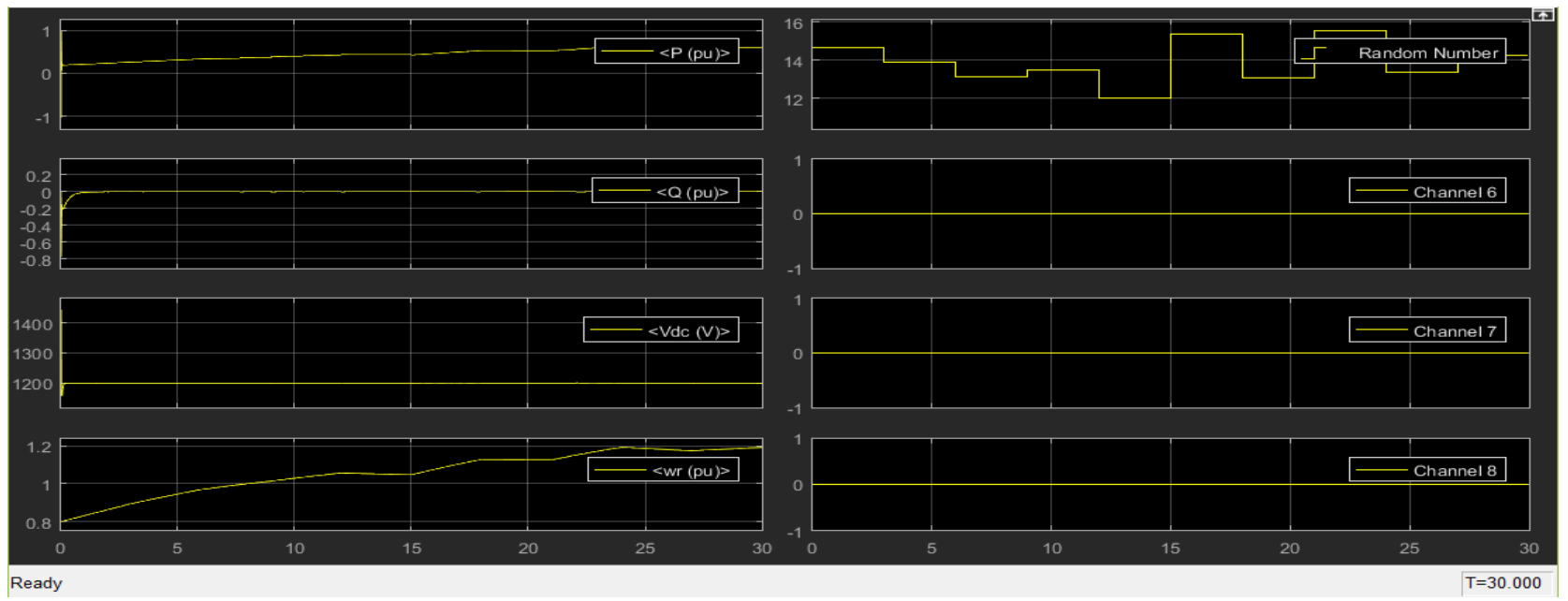

Figure 2 Variation curve of output characteristic of wind turbine

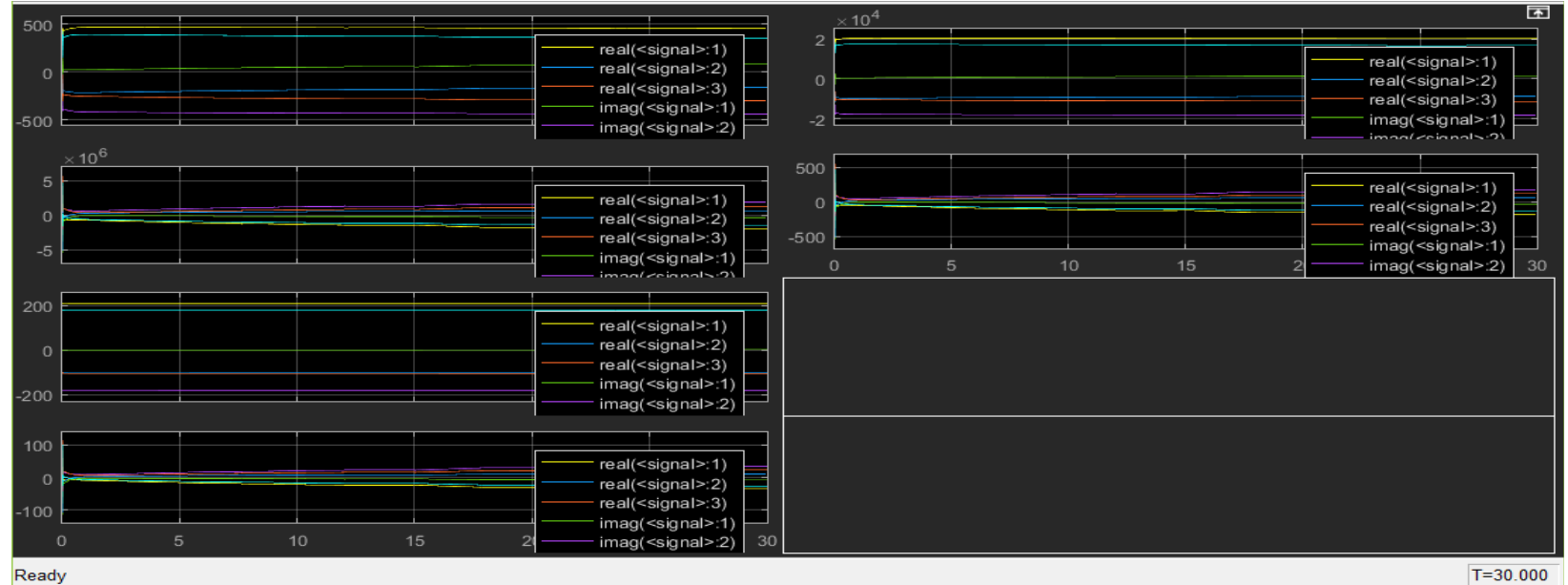

Figure 3 Output voltage and current waveforms of each node

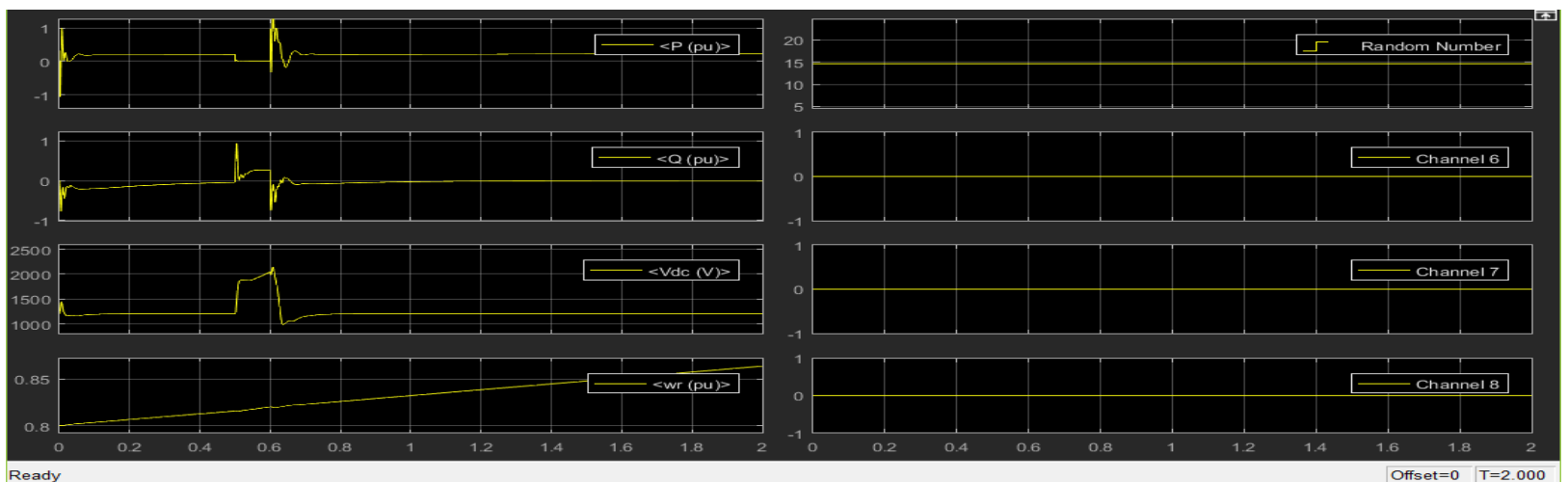




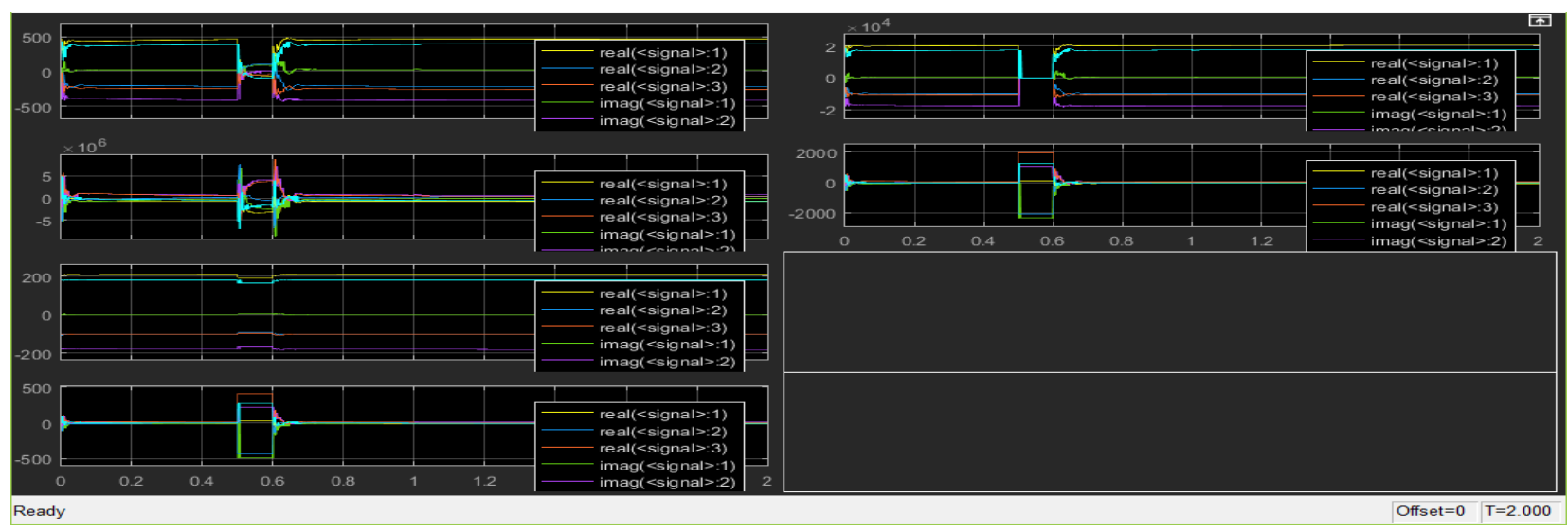

Figure 4 The output waveform when a three-phase ground fault occurs on a transmission line

\subsection{Simulation of Doubly-fed Variable-speed Wind Turbine under Power Grid Failure}

For fault analysis when the power grid fails, the threephase grounding fault and the single-phase grounding fault are simulated separately. Set the simulation time to $2 \mathrm{~s}$, set the fault start time to $0.5 \mathrm{~s}$, and the fault end time to $0.6 \mathrm{~s}$. The output waveform of the wind turbine is shown in Figure 4.

Through the three-phase grounding fault waveform, it can be seen that when the power grid fails, the voltage drops, and the active and reactive power vibrate violently. After the fault is eliminated, the normal operation state can be quickly restored.

\section{4 conclusion}

Through simulation, we can get the impact of wind power connected to the grid on the grid

1. The impact on relay protection. When a large amount of wind power is merged into the grid, the fault current of the wind farm may exceed the short-circuit current on the grid side. In this case, ignoring the wind farm will cause the protection range of the protection device to be extremely unreasonable and cause the protection device to malfunction. .

2 . Impact on power quality. The current largecapacity wind turbines are limited by the lack of suitable energy storage batteries, coupled with the fluctuation of wind speed, so the output of electric generators fluctuates up and down. At the same time, the wind direction and wind speed of the wind speed in different regions are quite different, and even the output of different units in the same region is different. This kind of uncertain and intermittent power transmission to the grid has a huge negative effect on the power quality of the power system, thus limiting the installed capacity of wind farms, and at the same time making it necessary to detect the power quality of wind turbines.

3 . The influence on line power flow and bus voltage. The integration of large-capacity wind turbines into the power system will change the power flow distribution at the access point. Whether the wind turbines used in wind power sites are fixed-speed wind turbines or variable- speed wind turbines can affect the power flow distribution of the wind farm.

Wind power generation may also provide a beneficial effect on the power flow and voltage of the system. For example, when the wind farm is close to the load, it reduces the loss on the transmission and distribution lines; the rapid reactive power control of the wind power farm can supplement the reactive power to maintain the generator when the grid fails.

\section{References}

1. Liu Baolan, Wen Huali. Current status and prospects of wind power generation in the world, 2000 ,

(4):12-14.

2. G.Li, C.Li, D.van.Hertem.HVDC grid:for offshore and supergrid of the future[M]. Wiley-IEEE Press, 2016.

3. FENG Y, LIN HY, HO SL, et al.Overview of wind power generation in China:Status and development[J].Renewable and Sustainable Energy Reviews, 2015 (50) :847-858.

4. XU J Z, HE D X, ZHAO X L. Status and prospects of Chinese wind energy[J]. Energy, 2010, 35(11):4439-4444.

5. Global installed wind power capacity in 2017Regional Distribution[OL]. 2018.

6. P.Bresesti, W.Kling, R.Hendriks, et al.HVDC connection of offshore wind farms to the transmission sy stem[J].IEEE Trans.Energy Convers, 2007, 22 (1):37-43. 